\title{
Sheehan's Syndrome: It is time to become more proactive in identifying this disease
}

Yara E. Tovar MD ${ }^{1}$, Waseem Ahmed MD ${ }^{1}$, Madhulika Urella MBBS ${ }^{1}$, Ayman H. Elkadry MD ${ }^{1}$, Rodhan A. Khthir MD ${ }^{1}$

\section{Author Affiliations:}

1. Marshall University Joan C. Edwards School of Medicine, Huntington, West Virginia

The authors have no financial disclosures to declare and no conflicts of interest to report.

\author{
Corresponding Author: \\ Waseem Ahmed MD \\ Marshall University Joan C. Edwards School of Medicine \\ Huntington, West Virginia \\ Email: mwaseemahmed92@gmail.com
}




\section{Abstract}

Sheehan's syndrome typically occurs as a result of ischemic pituitary necrosis due to severe postpartum hemorrhage and can present with varying degrees of pituitary insufficiency. It is more common in underdeveloped countries, and is frequently diagnosed years after delivery due to its nonspecific signs and symptoms. Failure to lactate is a common initial symptom, while many women also report amenorrhea or oligomenorrhea. This article presents a 26-year-old female with a history of hypertension who presented to the hospital for diarrhea, vomiting, and dizziness. Her blood pressure was $80 / 40 \mathrm{mmHg}$, requiring aggressive fluid resuscitation, after which it remained borderline. Further testing resulted in an ACTH stimulation test with inadequate response, secondary hypothyroidism, and low prolactin. Her menstrual period could not be assessed due to daily progesterone therapy for contraception. MRI of the brain showed an empty sella, after which she was diagnosed with Sheehan's syndrome, and started on hydrocortisone and levothyroxine.

\section{Keywords}

Sheehan's syndrome, postpartum hypopituitarism, postpartum pituitary gland necrosis, transient hypotension

\section{Introduction}

Pituitary infarction (Sheehan's syndrome) typically occurs as a result of ischemic pituitary necrosis due to severe postpartum hemorrhage and can present with varying degrees of pituitary insufficiency. It is uncommon in developed countries and is frequently diagnosed years after delivery due to its nonspecific signs and symptoms. Failure to lactate is a common initial symptom, while many women also report amenorrhea or oligomenorrhea.

\section{Case Presentation}

A 26-year-old female with past medical history of hypertension presented to the emergency department due to nausea, vomiting, and diarrhea. One day prior to admission she experienced dizziness, which resulted in a fall. Additionally, she had been complaining of marked weakness for the past several days. Upon arrival to the emergency department she was found to be hypotensive, with blood pressure of $80 / 40 \mathrm{mmHg}$. As a result, she received four liters of intravenous fluids, after which the blood pressure was $85 / 30 \mathrm{mmHg}$ with mean arterial pressure (MAP) of $48 \mathrm{mmHg}$. Even after aggressive fluid resuscitation, the patient's blood pressure remained borderline. At that time, other causes for the patient's hypotension were explored, such as Addison's disease.

The work-up resulted in a low random cortisol level of $0.6 \mathrm{ug} / \mathrm{dL}$, an inadequate response to an ACTH stimulation test of $0.7 \mathrm{pg} / \mathrm{mL} \rightarrow 3.5 \mathrm{pg} / \mathrm{mL} \rightarrow 5.0 \mathrm{pg} / \mathrm{mL}$, and a very low baseline ACTH level of less than $1.1 \mathrm{pg} / \mathrm{mL}$ (normal range $7.2-63.3 \mathrm{pg} / \mathrm{mL}$ ). This was followed by further investigation, revealing secondary hypothyroidism with a TSH of $0.861 \mathrm{U} / \mathrm{mL}$ (normal range $0.400-4.000 \mathrm{U} / \mathrm{mL}$ ) and free T4 of 0.19 (normal range $0.80-1.40 \mathrm{ng} / \mathrm{dL}$ ) as well as a low prolactin level of less than $0.2 \mathrm{ng} / \mathrm{mL}$ (normal range $1.9-25 \mathrm{ng} / \mathrm{mL}$ ). She had no evidence of 
diabetes insipidus and her menstrual cycle could not be adequately assessed since she was on continuous progesterone therapy for contraception after her delivery three years ago. At this point an MRI of the brain was done, which showed an empty sella. (Figures 1 and 2) Due to the patient's symptoms, laboratory findings, and imaging, the diagnosis of Sheehan's syndrome was made, and the patient started receiving hydrocortisone and levothyroxine.

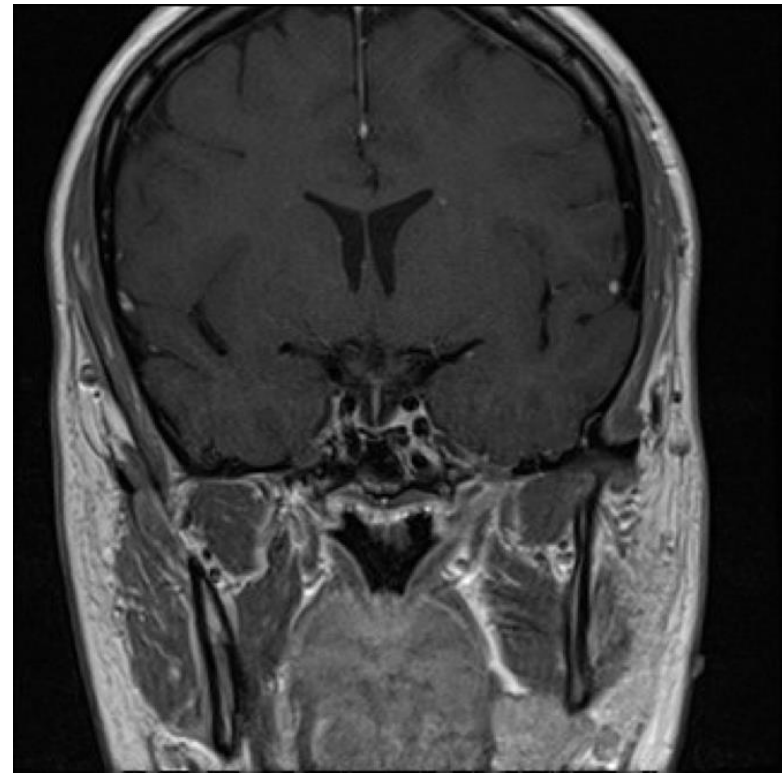

Figure 1: Coronal MRI of the brain showing an empty sella

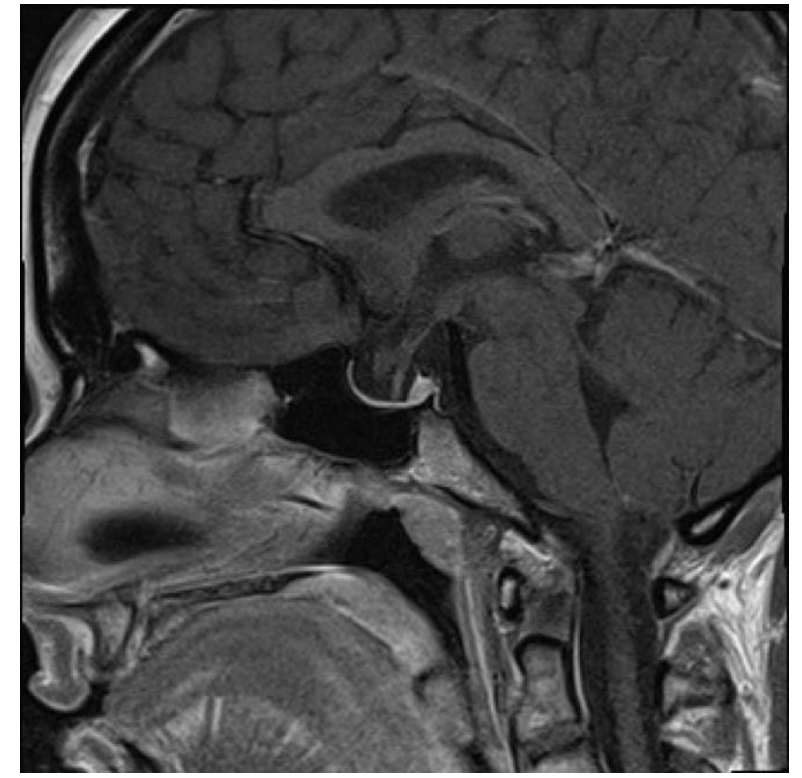

Figure 2: Sagittal MRI of the brain showing an empty sella

A detailed review of the patient's medical history showed that she had a complicated pregnancy with chronic hypertension, which resulted in her hospital admission for induction of labor at 39 4/7 weeks. During hospitalization she developed a fever, after which Cesarean section was performed, delivering a healthy $5 \mathrm{lb} 14 \mathrm{oz}$ female. During the procedure, she received Meperidine due to poor pain control, subsequently causing transient hypotension with blood pressure of 70/50 $\mathrm{mmHg}$. She was then given hetastarch in Sodium Chloride and resuscitated with intravenous fluids. There was no reporting of prolonged hypotension or postpartum hemorrhage. After the delivery, the patient did not breast feed and never resumed menses, which she assumed was secondary to treatment with daily progesterone tablets for contraception. She also stated that she always felt tired and never felt the same after the delivery.

\section{Discussion}

Sheehan's syndrome is a rare condition, usually secondary to postpartum hemorrhage, with the first case reported in 1937. The frequency of Sheehan's syndrome in developed countries now is rare, largely due to improvement in obstetric care and the availability of blood for transfusion. This could be one of the reasons that the diagnosis is sometimes overlooked and it is diagnosed years later when the patient is admitted for an acute problem. ${ }^{2}$ A significant number of patients present with nonspecific complaints including anorexia, fatigue, and weakness. 
Additionally, many of these patients have a mild form of this condition, which may also contribute to a delay in the diagnosis. The most common presenting symptoms are failure to lactate and menstrual abnormalities. ${ }^{3,4}$

A number of factors have been suggested to play a role in the pathogenesis of this condition. Physiological enlargement of the pituitary gland during pregnancy makes it more vulnerable to ischemia; as a result, a small decrease in blood pressure can precipitate pituitary infarction. The great majority of cases reported are due to massive postpartum hemorrhage. In developed countries, most cases reported are in the immigrant population. ${ }^{5}$ In developing countries like Turkey, postpartum bleeding remains the most common cause and the mean period of diagnostic delay is 20.37 years. $^{6}$

The diagnosis can be difficult and is based on clinical symptoms along with history of a complicated delivery. Patient presentation of hypopituitarism can vary from acute to insidious with very nonspecific symptoms. Once it is suspected, the diagnosis should be confirmed with a hormonal work-up and imaging evaluating the anterior pituitary gland. The treatment is focused on the replacement of hormones that are deficient. Adequate medical treatment is very important to reduce the morbidity and mortality in these patients. ${ }^{7}$ While the posterior pituitary is seldom involved, some cases have been described in the literature. ${ }^{8}$

We have presented a unique case where a patient developed Sheehan's syndrome after an episode of transient severe hypotension. The hypotension was likely the result of sepsis and the administration of Meperidine during the Cesarean section. We also believe that her exceptionally high blood pressure prior to the surgical delivery made her especially vulnerable to the effects of transient hypotension. Her diagnosis was delayed by three years because of nonspecific symptoms, as well as the fact that she was on continuous progesterone, which further masks symptoms. In conclusion, Sheehan's syndrome should be considered in any woman with symptoms of pituitary deficiency who had a complicated delivery, even when postpartum hemorrhage is not present. 


\section{References}

1. Sheehan HL. Post-partum necrosis of the anterior pituitary. Irish journal of medical science.

1948(270):241-55.

2. Diri H, Karaca Z, Tanriverdi F, Unluhizarci K, Kelestimur F. Sheehan's syndrome: new insights into an old disease. Endocrine. 2016;51(1):22-31.

3. Diri H, Tanriverdi F, Karaca Z, Senol S, Unluhizarci K, Durak AC, et al. Extensive investigation of 114 patients with Sheehan's syndrome: a continuing disorder. European journal of endocrinology. 2014;171(3):311-8.

4. Kelestimur F. Sheehan's syndrome. Pituitary. 2003;6(4):181-8.

5. Tessnow AH, Wilson JD. The changing face of Sheehan's syndrome. The American journal of the medical sciences. 2010;340(5):402-6.

6. Gokalp D, Alpagat G, Tuzcu A, Bahceci M, Tuzcu S, Yakut F, et al. Four decades without diagnosis: Sheehan's syndrome, a retrospective analysis. Gynecological endocrinology : the official journal of the International Society of Gynecological Endocrinology. 2016;32(11):904-7.

7. Kilicli F, Dokmetas HS, Acibucu F. Sheehan's syndrome. Gynecological endocrinology : the official journal of the International Society of Gynecological Endocrinology. 2013;29(4):292-5.

8. Góth A. Sheehan's Syndrome in Association with Diabetes Insipidus. British Medical Journal. 1963;1(5325):240. 